\title{
Development of Nutraceutical Product
}

\author{
Y. A. Yusof ${ }^{\# 1}$, C. J. Etti ${ }^{\# *}$, N. L. Chin ${ }^{\# 2}$

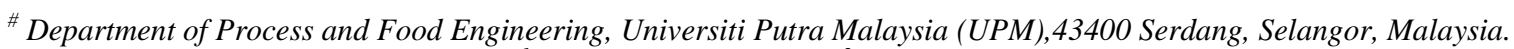 \\ E-mail: ${ }^{1}$ yus.aniza@upm.edu.my, ${ }^{2}$ chinnl@upm.edu.my \\ * Department of Agricultural and Food Engineering, University of Uyo, Nigeria \\ E-mail: ettichristopher@yahoo.com
}

\begin{abstract}
The aim of this study was to discuss the development of nutraceutical product which includes the current market trends, challenges, and exploitation of natural resources through various processing. Wet granulation and dry granulation techniques were adopted for such processes. Wet granulation covers high shear mixing granulation, fluidized bed granulation, and twin screw granulation. Dry granulation covers roll compaction and uniaxial die compaction. These techniques were compared and reviewed in terms of physical, chemical and toxicity studies. The physical study considered the particle size, density, morphology, flowability and dissolution. The chemical study discussed on the active ingredients in the nutraceutical products and the toxicity study was presented by investigation carried out on rats. There is a high potential for development of nutraceutical product. By understanding the various techniques of processing and characterisations, more nutraceutical products can be marketed.
\end{abstract}

Keywords - Nutraceutical; Wet granulation; Dry granulation; Natural resources; Characterisation.

\section{INTRODUCTION}

There is a substantial increase in demand for nutraceutical products by consumers which has resulted in a global nutraceutical exploit. This is as a result of the frequent adverse effects from pharmaceutical products, growing health care cost associated with conventional pharmaceuticals and the common acceptance of food-likesubstances to be harmless when compared with conventional pharmaceuticals. "Nutraceutical" is a term derived from "nutrition" and "pharmaceutical" by Stephen DeFelice, MD, a founder and chairman of the Foundation for Innovation in Medicine (FIM) in 1989, and defined it as "any substance that is a food or part of a food that provides medical or health benefits, including prevention and/or treatment of a disease"([1], [2]). "Nutraceutical" does not have marketing regulatory definition [3]. Nutraceutical products mainly consist of isolated nutrients such as vitamins, minerals, amino acids and fatty acids as well as dietary supplements like probiotics, prebiotics, antioxidants and enzymes. Genetically engineered designer foods, herbal products and processed foods like cereals, soups and beverages are also classified as nutraceutical product. The philosophy behind nutraceutical could be traced to a concept by Hippocrates (460-377 BC), the father of modern medicine who said, "Let thy food be thy medicine and the medicine be thy food". This statement was made in order to predict the connection between appropriate foods for health and their therapeutic benefits [4]. Increasing consumer interest and growing demands in nutraceuticals due to its health benefit and diseases prevention have compelled the accelerated development of new nutraceutical products in order to meet up with the demands. This article focused on the current market trends, challenges, processing techniques such as wet and dry granulation techniques, and characterisation of the various techniques through physical, chemical and toxicity studies adopted to produce new nutraceutical products from natural resources.

\section{Current Global Market Trend}

According to Narayan [5], in Frost and Sullivan report, the global market for nutraceuticals in 2011 was valued at \$149.5 Billion, the US, Europe, and Japan had the largest regional markets accounting for almost $93 \%$ of the global nutraceuticals demands. This market is almost saturated, with exceedingly high per capita spends on nutraceutical products, hence compelling manufacturers to look at developing countries such as India and China, which have considerably lower per capita spend on nutraceutical products, as key growth regions for their nutraceuticals collection [5]. The market size is forecast to grow to $\$ 210$ Billion in 2016 at $7.0 \%$ compound annual growth rate (CAGR) [5]. This current global growth is a motivation for improved processing and characterization procedures in 
order to develop new nutraceutical products that can meet up with the global demands.

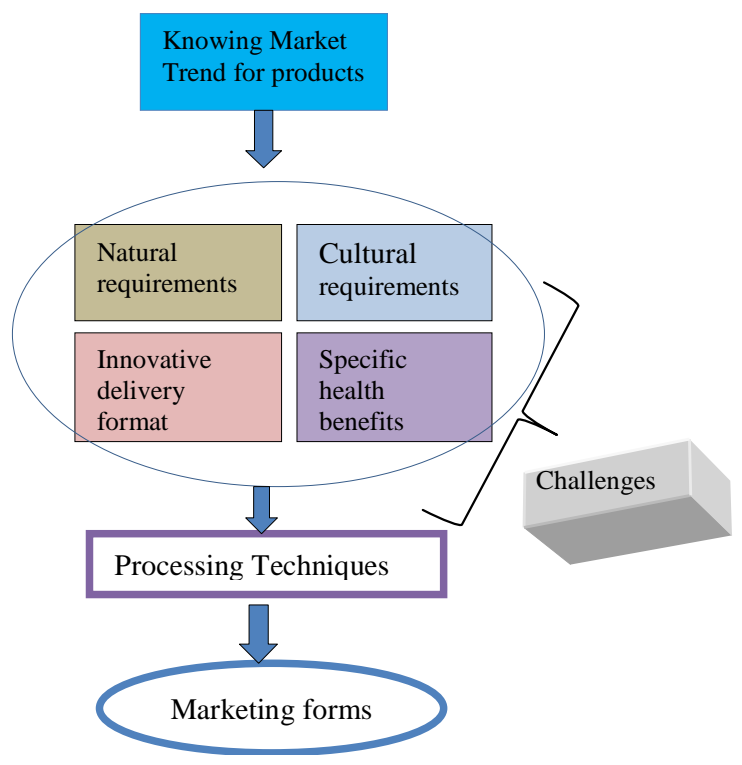

Fig. 1 Development of Nutraceutical Products require the understanding of these steps

\section{CHALLENGES}

Nutraceutical is a relatively new field and so it has a wider knowledge gap for researchers to explore with several challenges. Fig. 1 shows the steps in development of nutraceutical products. In this field, there is a paradigm change from single agent efficacy of the established pharmaceutical model to a widely accepted health promoting food properties that are not necessarily single components, but rather of several active ingredients. The methodologies for handling and measuring of these several active ingredients and bioactive phytochemicals are limited and thus, becoming a challenge in this relatively new field. There is also a problem of specific claims of health benefits on products labels as manufacturers would want to have, but these claims need solid scientific evidence which is presently not there [6]. The field of nutraceutical is also challenging to government regulatory agencies as it is in between foods and pharmaceuticals. The increasing awareness of consumers in nutraceuticals is also a challenge to manufacturers because customers are now being informed to seek name-brand products to guarantee superior quality, even with a little higher price [6]. Understanding of certain cultures is of concern to manufacturers of nutraceutical products because cultures have certain requirements for specific products. Therefore, understanding of such cultural requirements is inevitable to manufacturers in order to control the latest development of such nutraceutical products [5]. Also, there is a challenge of formulating nutraceutical products into traditional foods and beverage products, because stability has always been a concern to manufacturers on how to incorporate functional ingredients to existing products. Development of innovative products as a result of adequate knowledge of certain processing techniques which this article aims to address could be a way of solving this stability problem. Currently, the nutraceutical products are available in tablets, capsules, tinctures, beverages and etc. Tablets are the most commonly used for nutraceutical powder product delivery due to its uniform size and shape, attractive appearance, longer shelf life, easy for storage, and more economical. Development of nutraceutical in tablet form was given a particular attention. Various processing techniques that are available for development of nutraceutical products were presented. This paper discussed the processes involved, the material properties, flowability and dissolution characteristics of nutraceutical powders by adopting the pharmaceutical product processing techniques. Chemical characterization was briefly introduced. Other than that, the toxicity study on rats was also considered.

\section{GRANULATION TECHNIQUES}

Granulation is the process of collecting particles together by creating bonds between them. These bonds are formed by compression or through the use of a binding agent. The granulation process combines one or more powders to form a granule that predicts the tableting process and yield quality tablets within the required tablet-press speed range. Joining particles within a given granulation process improves flow and compression characteristics, reduces segregation, improves content uniformity, and eliminates excessive amounts of fine particles. Thus, resulting in improved yield, reduced tablet defects, increased productivity and reduced down time. The objective of the granulation process is to combine ingredients to produce a quality tablet. When powders are very fine, fluffy, not stay blended, or will not compress, then they must be granulated. Pharmaceutical products are processed all over the world using the wetgranulation, or dry-granulation methods, depending on the ingredients, individual characteristics and ability to properly flow, compress, eject, and disintegrate. Choosing a method requires thorough investigation of each of the ingredients in the formula, the combination of ingredients, and how they work with each other. Then the proper granulation process can be applied.

\section{A. Wet Granulation}

Wet granulation, the process of adding a liquid solution to powder, is one of the most common ways to granulate. In wet granulation, granules are formed by the addition of a granulation liquid onto a powder bed which is under the influence of an impeller (in a High shear granulator, screws (in a twin screw granulator) or air (in a fluidized bed granulator) [7]. In wet granulation, liquid bridges develop between particles with tensile strength. Surface tension forces and capillary pressure are primarily responsible for initial granulation and strength [7]. Wet granulation is the oldest and most common granulation technique and can be accomplished using different types of equipment, including high-shear, fluid-bed, and twin-screw granulators. It involves blending at high and/or low shear forces with the addition of a liquid. In fluid-bed granulation, for example, an atomized liquid is sprayed from the top or bottom directly onto the solids under a continuous air stream with little or no shear. Wet granulation can be divided into three main processes of low shear, high shear, and fluid bed granulation. Traditional wet granulation, is the process of mixing and adding solution (wet massing) and then transferring the 
product to the fluidized bed and the tray dryer. Wet massing is the process of adding a solution to a blended powder and mixing for a predetermined period of time at a given mechanical speed.

\section{B. Dry Granulation}

Dry granulation process is used to form granules without using a liquid solution because the product granulated may be sensitive to moisture and heat. Recent advances in formulation technologies have led to a shift from traditional wet granulation to dry granulation manufacturing process in the development of solid oral dosage forms. Dry granulation can be led under two methods, either an extensive tablet (slug) is delivered in a substantial obligation tableting press or the powder is pressed between two counter-turning rollers to deliver a persistent sheet or lace of materials (roller compactor, usually referred to as a chilsonator). The roller compactor (granulator-compactor) uses an auger-feed system that will reliably convey powder consistently between two weight rollers. The powders are compacted into a ribbon or little pellets between these rollers and processed through a low-shear mill. At the point when the product is compacted properly, then it can be passed through a mill and used as final blend before tablet compression.

\section{Uniaxial Die Compaction}

Die compaction is a dry granulation compression technique and it is the most extensively used method of tableting production. Uniaxial die compaction is one of the numerous conspicuously different types of die compaction. It has one dynamic pressing action (plunger) and it involves an upper punch movement. The movement of the plunger (force transmitter), can be subdivided into two stages, compression and decompression. During compression (loading), the plunger moves into the upper punch of the die (Figure 2a), making the powder dense and the particles to rearrange forming aggregates with cohesive strength due to inter-particle forces such as Van der Waals forces, mechanical interlocking and formation of solid bridges [8]. As space between the upper and lower punches decreases, the applied pressure and density of the particle increases. And as the applied pressure increases, the elastic and plastic deformation of component particles becomes dominant. This process is referred to as compaction and it describes a condition where the particles may undergo elastic and plastic deformations, particle fractures as well as inter-particulate bonding, and both inter-particulate and particle-die wall friction [8]. A material that has completely recovered from applied pressure is known to have gone through elastic deformation while a material that has been permanently deformed either through applied pressure or particle fracturing is known to have been through plastic deformation. For decompression (unloading) process (Figure 2b), the plunger begins to move away from the die upper punch making the applied pressure to drop rapidly as the plunger (force transmitter) is removed and thus increasing the space between the two punches. Due to the effect of stress relaxation, some of the elastic strain produced compression will recover its volume [8] (Figure 2c), which increase powder bed volume due to the decrease in relative density. Relative density usually decrease as powder bed volume increases due to less close packing of the particles [9]. Stress relaxation is related to elastic recoveries of a material. The rate of elastic recovery during the process of decompression is seen as one of the key factors responsible for the volume of defects, such as cracks and fractures of tablets due to faster elastic recovery rate and entrapment of air that prevents strong bonding during compression step [8]. In the ejection stage (Figure $2 \mathrm{~d}$ ), the applied pressure rise again as the plunger (force transmitter) closes up the upper punch of the die, so as to eject the tablet.

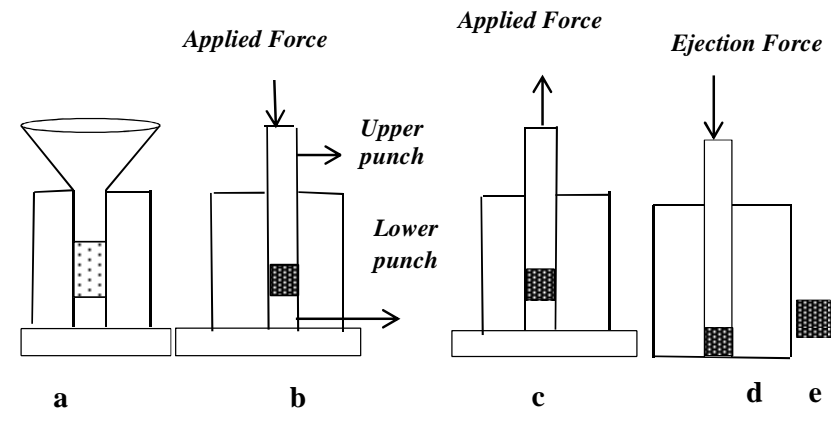

Fig. 2 Schematic Diagram Showing Uniaxial Die Compaction Cycle Including; (a) Die Filling, (b) Compression Relaxation/Loading, (c) Decompression Relaxation/Unloading, (d) Ejection, (e) Tablet

\section{MATERIAL PROPERTIES}

The material properties considered here are particle size and density which include true, bulk and tapped densities (see Table 1). The densities are used to calculate the powder flowability.

\section{A. Particle Size}

A small change in particle size can cause substantial alterations in the resulting material flowability. Reduction in particle size of the material often tends to decrease the flowability of the given granular material due to increasing surface area per unit mass [10]. For example, Farely and Velantin [11] studied the influence of particle size distribution on bulk powder properties and realized that particle size was the most important factor governing the 'structure' of the powder compact, and at the same time, the inter-particulate force that governs the strength of the 'structure'. Particle size is also important in the compressibility of powders. An increase in particle size generally leads to a corresponding increase in compressibility (and hence volume reduction) [12]. In a mass flow scenario, if the particles are less than $1 / 4$ inch in size, then it is most likely that cohesive arching will occur during discharge [13]. The finer the particle size and greater the range of particle sizes, the greater the cohesive strength, and lower the flow rate [13]. Reduction in particle size increases the contact area between the particles, thereby increasing the cohesive force which reduces the flowability.

\section{B. Density}

Densities of powder material are influenced by particle size and shape of the powder material. Densities are important in powder properties and are briefly reviewed below. Generally, density helps to determine a coherent tablet as a higher density is usually related to have a higher 
tensile strength and also represent a better compressibility of compressed powder as it has less porosity in tablet.

\section{True Density}

True particle density is defined as the ratio of the weight of powder particle to its volume excluding open and closed pores [14]. Theoretically, the true density can be measured by calculation using the equation below;

$$
\rho_{t}=\frac{w_{t}}{v_{t}}
$$

where $\rho_{t}, w_{t}$ and $V_{t}$ are true density $\left(\mathrm{kgm}^{-3}\right)$, weight of the powder $(\mathrm{kg})$ and the true volume of the powder $\left(\mathrm{m}^{3}\right)$, respectively

\section{Bulk And Tapped Densities}

Bulk density can be identified as the volume occupied by the solid plus the volume of voids when divided into powder. Whereas, tap density is a different type of bulk density obtained by tapping or vibrating the container in a particular method to achieve more effective particle parking and therefore, it is usually higher than bulk density [15];

$$
\rho_{b}=\left(\frac{W_{t}}{V_{b}}\right)
$$

where $w_{t}$ is weight of the powder, $\boldsymbol{V}_{b}$ is volume of the powder obtained from tarred graduated cylinder without tapping. The tapped density $\left(\rho_{\text {rap }}\right)$ of the powders was calculated by using the following equation;

$$
\rho_{t a b}=\left(\frac{w_{t}}{V_{t a}}\right)
$$

where $w_{t}$ is the weight of powder, $V_{t a}$ is the volume of the powder bed after 500 taps or until a constant volume is reached.

\section{E. Carr Index And Hausner Ratio}

Carr Index and Hausner Ratio are used in describing the flowability of powder. Carr Index $(C I)$ can be determined as the ratio of the difference of the tapped and the bulk densities to the tapped density [16]. According to Carr [16], who constructs the flowability index, an excellent flowability is between the Carr Index of 5\% to $15 \%$ while Carr Index of above $25 \%$ normally shows poor flowability.

$$
C I=\frac{\rho_{\text {tap }}-\rho_{b}}{\rho_{\text {tap }}}
$$

Hausner Ratio $(H R)$ was also used to characterize the flowability of the powder, which can be determined by the ratio of the tapped density to that of bulk density [17]. $H R$ of 1.0 to 1.1 , powder was considered as free flowing, $H R$ greater than 1.1 to 1.25 , powder was classified as medium flowing, $H R$ greater than 1.25 to 1.4 , the powder was classified as difficult to flow and $H R$ higher than 1.4, powder was considered to be very difficult to flow [18];

$$
H R=\frac{\rho_{\text {tap }}}{\rho_{b}}
$$

\begin{tabular}{|c|c|c|c|c|c|c|}
\hline \multirow[t]{2}{*}{ Material } & \multirow{2}{*}{$\begin{array}{c}\text { Particle } \\
\text { Size } \\
(\mu \mathrm{m})\end{array}$} & \multicolumn{3}{|c|}{ Density $\left(\mathrm{kg} / \mathrm{m}^{3}\right)$} & \multirow{2}{*}{$\begin{array}{c}\text { Carr } \\
\text { Index } \\
(1965) \\
(\%) \\
\end{array}$} & \multirow{2}{*}{$\begin{array}{c}\text { Hausner } \\
\text { Ratio } \\
\text { (1967) } \\
\text { (HR) } \\
\end{array}$} \\
\hline & & Bulk & Tap & True & & \\
\hline $\begin{array}{c}\text { Orthosiphon } \\
\text { stamineus }\end{array}$ & $\begin{array}{l}16.4 \\
\pm 0.1\end{array}$ & $\begin{array}{l}589.9 \\
\pm 1.0\end{array}$ & $\begin{array}{c}893.4 \\
\pm 1.0\end{array}$ & $\begin{array}{c}1628.5 \\
\pm 5.1\end{array}$ & $\begin{array}{l}33.96 \\
\pm 0.3\end{array}$ & $\begin{array}{l}1.51 \\
\pm 0.0\end{array}$ \\
\hline $\begin{array}{c}\text { Eurycoma } \\
\text { longifolia } \\
\text { Jack }\end{array}$ & $\begin{array}{l}26.0 \\
\pm 0.4\end{array}$ & $\begin{array}{l}438.7 \\
\pm 0.6\end{array}$ & $\begin{array}{c}645.1 \\
\pm 0.7\end{array}$ & $\begin{array}{c}1304.3 \\
\pm 0.4\end{array}$ & $\begin{array}{l}32.0 \\
\pm 0.1\end{array}$ & $\begin{array}{l}1.47 \\
\pm 0.0\end{array}$ \\
\hline $\begin{array}{c}\text { Andrographis } \\
\text { paniculata }\end{array}$ & $\begin{array}{l}15.6 \\
\pm 3.4\end{array}$ & $\begin{array}{l}589.8 \\
\pm 0.4\end{array}$ & $\begin{array}{c}879.7 \\
\pm 0.5\end{array}$ & $\begin{array}{c}1612.6 \\
\pm 0.0\end{array}$ & $\begin{array}{c}32.96 \\
\pm 0.0\end{array}$ & $\begin{array}{l}1.49 \\
\pm 0.0\end{array}$ \\
\hline
\end{tabular}

TABLE I

MATERIAL PROPERTIES OF SOME HERBAL POWDERS. SOURCE: [19]

\section{F. Flowability}

Flowability is the ability of granular solids and powders to flow. Flow behaviour is multidimensional in nature, and it depends on many physical characteristics. Flowability, in fact, is a consequence of the combination of a material's physical properties that influence material flow, environmental conditions, and the equipment used for handling, storing, and processing these materials [20]. Because of this, no single test can fully quantify a product's flowability. Some of the factors that affect flowability of bulk solids and powders include moisture content, humidity, temperature, pressure, fat, particle size, and flow agents. Fig 3 shows the powder flow function of Ficus deltoidea, Acdisol and Avicel adapted from [21]. Here it was noticed that Acdisol and Avicel flow function lines showed better flowability with increase in major consolidation stress (MCS) compared to Ficus deltoidea. From the graph, the steepness of the flow function lines determines the difficulty of the powder to flow.

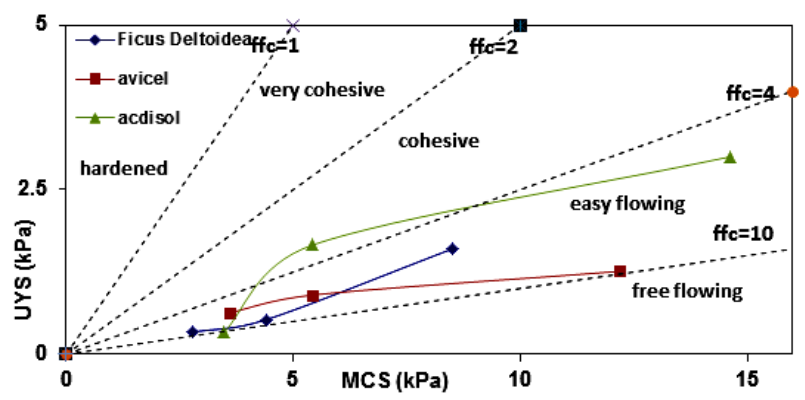

Fig. 3 Powder flow functions. Source: [21]

\section{DISSOLUTION}

Dissolution is a process by which a solid solute enters a solution. Tablet dissolution is a standardized method for measuring the rate of drug release from a dosage form. The standardized conditions of liquid/solid interface, temperature and solvent composition are considered. Fig 4 shows the effect of effervescent agent concentration on the dissolution rate of mango fruit tablets [22]. Increasing concentrations of 
effervescent agents caused the dissolution time to reduce drastically as shown in Fig 4 [22].

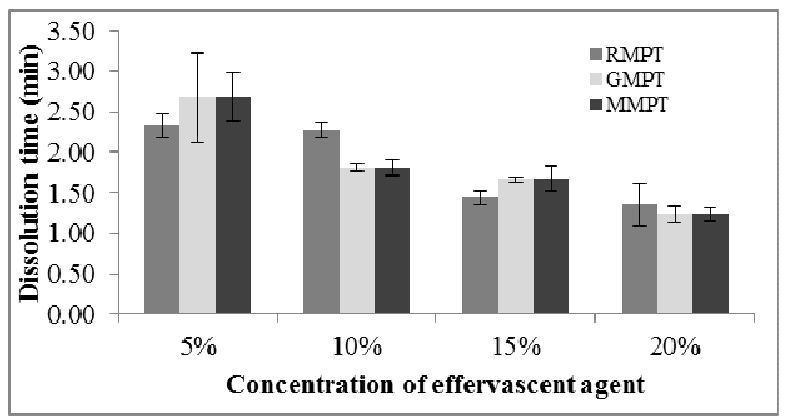

Fig. 4 Effects of effervescent agent concentration on the dissolution rate of mango fruit tablets. Dissolution was carried out in vitro in distilled water. (RMPT $=$ Ripe mango fruit tablet, GMPT $=$ Green mango fruit tablet, and MMPT= Mixed mango fruit tablet) Source: [22]

\section{CHEMICAL CHARACTERISATION}

Tin layer chromatography (TLC), high performance liquid chromatography (HPLC), nuclear magnetic resonance (NMR) and spectrophotometric methods are some of the various methods that can be used to identify and characterise various active ingredients from plants or herbal materials [23]. The characterisation are done after the extraction of ingredients through any of the following extracting procedures such as Phytonics Process, Supercritical Fluid Extraction, Ultrasound Extraction (Sonication), Counter-Current Extraction, Aqueous Alcoholic Extraction by Fermentation and Hot Continuous Extraction (Soxhlet). Extraction involves the separation of medicinally active portions of plant or animal tissues from the inactive or inert components by using selective solvents in standard extraction procedures [23]. The products so obtained from plants are relatively impure liquids, semisolids or powders intended only for oral or external use. Certain factors are responsible for the choice of the extraction methods, such as; sensitivity of the active ingredients with respects to temperature, solubility of the solvents used, cost of the overall extraction process, threats of extraction method to the environment, cost of energy involved and flammability and toxicity of the solvents used for the extraction.

\section{TOXICITY STUDY}

The evaluation of toxicity and safety is required by law for every new product or therapy offered by the medical device, chemical or pharmaceutical industry. The basic goal of this toxicology assessment is to identify the side effects that a substance or product may cause in humans. A key stage in ensuring the safety of this product is to conduct toxicity tests in appropriate animal models, and acute toxicity studies and repeated dose toxicity tests are few of toxicity tests that are used. Acute oral toxicity (AOT) test and Sub-chronic toxicity test (repeated dose study) on female rats according to OECD 423 [24] guidelines for AOT and OECD 407 [25] guidelines for repeated dose study are normally adopted for the studies. Haematological, biochemical and histological profiles of the treated rats are often analysed. Some in vitro analysis can also compliments the animal study for necessary assurance. Figs. 5 (a and b) shows the histology of kidney of a normal rat (Fig. 5a) and kidney of a rat treated with $200 \mathrm{mg} / \mathrm{kg} \mathrm{L}$ of Labisia pumilia beverage mix (Fig. 5b). The kidney of the treated rat shows no differences with the normal kidney which can be concluded that consumption of the beverage mix is safe.
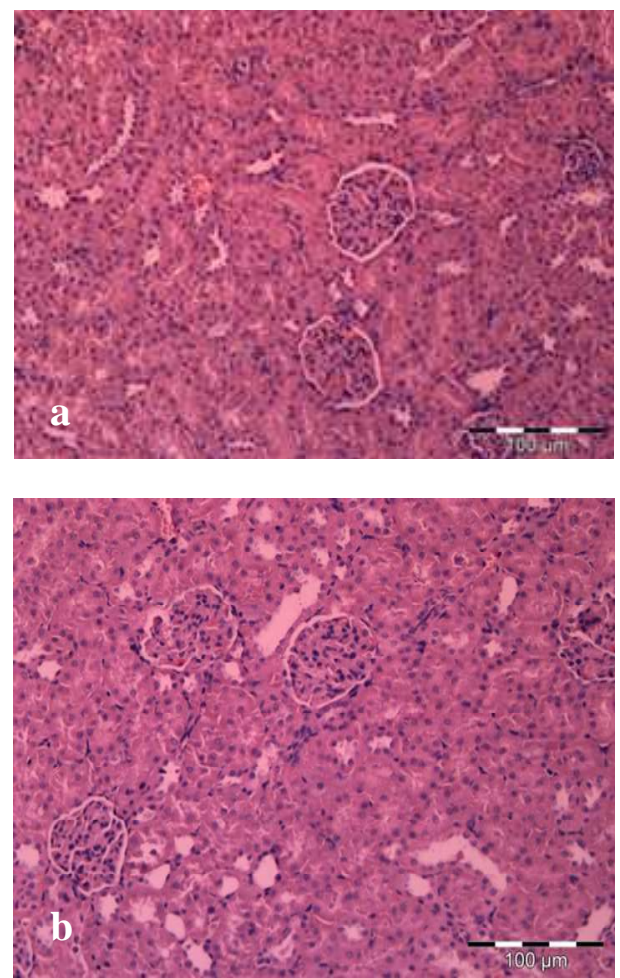

Fig. 5 (a) Kidney of a normal rat and (b) kidney of a rat treated with 200 $\mathrm{mg} / \mathrm{kg}$ L of Labisia pumilia beverage mix for 28 days.

\section{CONCLUSIONS}

Nutraceutical products are fast developing with an increasing market trend because of the growing consumer demands as a result of its benefits and diseases prevention. The challenges of specific claims of ingredients and health benefits, regulatory requirements, cultural requirements and innovative processing techniques could be solved through adequate knowledge and research into this new field of study. Understanding of granulation techniques, physical, flowability and toxicological properties of food and herbal powders would accelerate the development of nutraceutical products.

\section{NOMENCLATURE}

$\begin{array}{lll}\rho_{t} & \text { true density of powder } & \mathrm{kgm}^{-3} \\ w_{t} & \text { weight of powder } & \mathrm{kg} \\ V_{t} & \text { true volume of powder } & \mathrm{m}^{3} \\ \rho_{b} & \text { bulk density of powder } & \mathrm{kgm}^{-3} \\ V_{b} & \text { volume of powder } & \mathrm{m}^{3} \\ \rho_{t a b} & \text { tap density of powder } & \mathrm{kgm}^{-3} \\ V_{t a} & \text { volume of powder after } 500 \text { taps } & \mathrm{m}^{3} \\ C I & \text { Carr Index } & \\ H R & \text { Hausner Ratio } & \end{array}$




\section{REFERENCES}

[1] D. F. L. S. Stephen, "The nutraceutical revolution, its impact on food industry," Trends in Food Science and Technology, vol. 6, pp. 59-61, 1995.

[2] V. Brower, "Nutraceuticals: Poised for a healthy slice of the healthcare market?" Nature Biotechnology, vol. 16, pp. 728-731, 1998

[3] S. H. Ziesel, "Regulation of 'Nutraceuticals'," Science, vol. 285, pp. 1853-1855, 1999.

[4] D. Bagchi, "Nutraceuticals and functional foods regulations in the United States and around the world," Toxicology, vol. 221, no. 1, pp. 1-3, 2006.

[5] V. C. Narayan, "Sizing up the market for Nutraceutical products in India and forecasting opportunities in the long term," Nutraceuticals India, 2012.

[6] E. Sohaimy, "Functional foods and nutraceutical-modern approach to Food Science," World Applied Sciences Journal, vol. 20, no. 5, pp. 691-708, 2012.

[7] R. M. Dhenge, K. Washino, J. J. Cartwright, and M. J. Hounslow, "Twin screw granulation using conveying screws: Effects of viscosity of granulation liquids and flow of powders," Powder Technology, vol. 238, pp. 77-90, 2013.

[8] C. Wua, O. M. Ruddy, A. C. Bentham, B. C. Hancock, S. M. Best, and J. A. Elliott, "Modelling the mechanical behaviour of pharmaceutical powders during compaction.," Powder Technology, vol. 152 , pp. $107-117,2005$.

[9] F. O. Ohwoavworhua, T. A. Adelakun, and O. O. Kunle, "A Comparative Evaluation of the Flow and Compaction Characteristics of $\alpha$-Cellulose obtained from Waste Paper," Tropical Journal of Pharmaceutical Research, vol. 6, no. 1, pp. 645-651, 2007.

[10] J. J. Fitzpatrick, T. Iqbal, C. Delaney, T. Twomey, and M. K. Keogh, "Effects of powder properties and storage conditions on the flowability of milk powders with different fat contents," Journal of Food Engineering, vol. 64, pp. 435-444, 2004.

[11] R. Farely and F. H. H. Valentin, "Effect of particle size upon strength of powders," Powder Technology, vol. 1, pp. 344-354, 1967.

[12] H. Yan and G. V. Barbosa-Canovas, "Compression characteristics of agglomerated food powders: effect of agglomerate size and water activity," Food Science and Technology International, vol. 3, no. 5, pp. 351-359, 1997.
[13] J. A. Marinelli and J. W. Carson, "Solve solids flow problems in bins, hoppers and feeders," Chemical Engineering Progress, vol. 88, no. 5, pp. 22-28, 1992.

[14] V. B. C. Gustavo and P. Juliano, "Physical and chemical properties of food powders. In Encapsulated and powdered foods, ed. Onwulata, C," United State of America: Taylor and Francis Group, pp. 39-67, 2005.

[15] S. Lowell and J. E. Shields, "Density measurement. In Powder Surface Area and Porosity, ed. B. Scarlett," London, New York: Chapman and Hall, pp. 217-221, 1984.

[16] R. L. Carr, "Evaluating flow properties of solids," chemical Engineering, vol. 72, pp. 163-168, 1965.

[17] H. H. Hausner, "Friction conditions in a mass of metal powder," International Journal of Powder Metallurgy, vol. 3, no. 4, pp. 7-13, 1967.

[18] G. D. Hayes, Food Engineering Data Handbook. New York: Longman Scientific and Technical, 1987.

[19] Y. A. Yusof, A. A. Hamid, S. Ahmad, N. A. Razak, N. L. Chin, and S. Mohammed, "A comparison of the direct compression characteristics of Andrographis peniculata, Eurycoma longifolia jack, and Orthosiphon stamineus Extracts for Tablet development," in New Tribiological Ways, Australia: in Tech, Vienna. ISBN 978-953307-206-7, 2011.

[20] J. K Presscott and R. A. Barnum, "On powder flowability," Pharmaceutical Technology, pp. 60-84, 2000.

[21] F. S. Mohd Salleh, Y. A. Yusof, M. S. Anuar, and N. L. Chin, "Understanding the Tabletting Characteristics of $\mathrm{F}$ icus deltoidea Powder by Fitting into Compression Models," Journal of Food Process Engineering, pp. 1-12, Nov. 2014.

[22] M. Y. Ong, Y. A. Yusof, M. G. Aziz, N.L. Chin, and N. A. Mohd Amin, "Characterisation of fast dispersible fruit tablets made from green and ripe mango fruit powders," Journal of Food Engineering, vol. 125 , pp. 17-23, 2014

[23] S. S. Handa, S. P. S. Khanuja, G. Longo, and D. D. Rakesh, "Extraction technologies for medicinal and aromatic plants," International centre for science and high technology, 2008.

[24] "OECD. 2001. Guidelines for the Testing of Chemicals OECD 423 Acute Oral Toxicity-Acute Toxic Class Method Organisation for Economic Cooperation and Development, Paris," 2001.

[25] "OECD. 2008. Guidelines for the Testing of Chemicals OECD 407 Acute Oral Toxicity-Acute Toxic Class Method Organisation for Economic Cooperation and Development, Paris," 2008. 